\title{
Societal impact and economic value of spine surgery in Brazil
}

\author{
Emiliano Vialle ${ }^{1}$
}

Received: 13 April 2015/Accepted: 17 April 2015/Published online: 8 May 2015

(C) Springer-Verlag France 2015

Brazil's economic growth in the past decade has aroused global attention towards a promising market in several areas. Evident limitations emerged, as national infrastructures did not meet the country's need for expansion.

The health system allows for global medical care, which of course has lead to ever-increasing expenses in health costs as the demand for new treatment grows. Private health insurances cover around one-fourth of the population, who seeks better medical care than that provided by the government policies, with around 50 million people (80 \% in collective health plans, usually funded by employers, and $20 \%$ privately funded) and an estimate individual expense of US \$50/person/month [1].

There are also huge discrepancies when comparing medical care in Northern and Southern Brazil, regarding numbers of physicians and hospitals, and number of patients under a private medical insurance policy.

Although no official data are available, the number of spine procedures has grown disproportionately when comparing the private and public medical systems, and specific measures could be introduced by learning from both Europe and North America, thus avoiding unnecessary expenses and future restrictions over spine surgery in Brazil, like those seen in other countries. This increase in the cost of medical care has entailed significant increments in medical insurance monthly fees, above the country's inflation rate, which, however, has not translated into better medical reimbursement.
Disease characteristics mirror this discrepancy, with treatments ranging from state of the art technology for disc herniations, and in situ fusions for spine tuberculosis.

The ethnic diversity that constitutes the Brazilian population also brings a variety of problems that are not seen as frequently elsewhere in the world allowing Brazilian spine surgeons to develop an extensive experience in surgical management of spine pathologies.

Unfortunately, the language barrier, lack of infrastructure for research and long working hours limit the number of scientific contributions produced by the Brazilian spine community.

Finally, this ArgoSpine supplement to EJOST is an opportunity for medical peers to have an overview of some technical and societal aspects of spine surgery in Brazil, hopefully leading to future collaborations and improvement in medical care for both surgeons and patients.

Conflict of interest None.

\section{Reference}

1. Brazilian Medical Council (2015) http://portal.cfm.org.br/index. php?option=com_content\&view=article\&id=22200:informacoessobre-a-saude-suplementar-no-brasil\&catid=3. Accessed Jan 30, 2015

Emiliano Vialle

evialle@hotmail.com

1 Curitiba, Brazil 